\title{
How can we evaluate EFA advocacy and coordination? Case of the E-9 Initiative
}

\author{
Hiroshi Ito \\ University of Paris I Pantheon-Sorbonne \\ 12 Place du Pantheon, 75005 Paris, France \\ Tel: 33-1-4407-8000Ｅ-mail: Hiroshi.Ito@malix.unive-paris1.fr
}

Received: October 18, 2012 Accepted: October 30, 2012 Published: November 1, 2012 doi:10.5296/jse.v2i4.2585 URL: http://dx.doi.org/10.5296/jse.v2i4.2585

\begin{abstract}
UNESCO has long been engaged in education advocacy and coordination work. However, few tools have been suggested to evaluate its effectiveness in these areas. This paper examines and evaluates the E-9 Initiative, one of UNESCO's EFA advocacy and coordination activities, through an analysis of the Initiative's visibility in UNESCO's Executive Board and General Conference documents.
\end{abstract}

Keywords: Education for All (EFA), EFA coordination mechanisms, monitoring and evaluation, E-9 Initiative, South-South Cooperation 


\section{Introduction}

The United Nations Educational, Scientific, and Cultural Organization (UNESCO) has long been associated with its engagement in education advocacy and coordination at the global, regional, and national levels, although its activities are not limited to these realms alone. Education for All (EFA) is a prime example of UNESCO's advocacy and coordination endeavor to promote quality basic education for all (UNESCO, 2012). In addition to UNESCO, four other convening agencies (i.e., the World Bank, UNICEF, UNDP, and UNFPA) and other stakeholders such as national governments and civil society have been in support of EFA.

Some, including UNESCO's own Member States, critique UNESCO's function in EFA and argue the importance of monitoring and evaluating UNESCO's task. Yet few, if any, have developed tools for measuring the impact of EFA advocacy and coordination in part because the correlation between advocacy/coordination and its outcomes is difficult to quantify and thus remains unclear (UNESCO, 2011a). This paper seeks to reverse this trend by examining a specific component of UNESCO's EFA advocacy and coordination work. A case study of the E-9 Initiative was conducted focusing on its visibility ${ }^{\mathrm{i}}$ in UNESCO's official documents: the Executive Board (EXB) and the General Conference (GC) documents. ${ }^{\text {ii }}$ Visibility here denotes how many EXB and GC documents and their sections describe E-9 issues and how often the term "E-9" appears in these documents. Despite the fact that visibility may not articulate the relationship between advocacy/coordination and its outcome, this paper argues that visibility of the initiative in official documents can be one of the tools utilized to measure advocacy/coordination activities, revealing at least part of its importance and recognition. It may be important to note that this research intends to develop further discussion between stakeholders in EFA advocacy and coordination efforts that include the E-9 Initiative.

\section{EFA Advocacy and Coordination}

Advocacy is defined as "public support for or recommendation of a particular cause or policy" and coordination is "the organization of the different elements of a complex body or activity so as to enable them to work together effectively" (Oxford English Dictionary 2012). Following these definitions, the function of EFA advocacy and coordination like the E-9 Initiative is to promote EFA and bring EFA partners (e.g., Member States, development organizations) together for the attainment of EFA. In this respect, the success (or failure) of the E-9 Initiative can be measured partly through the EFA indicators ${ }^{\mathrm{iii}}$ in the E-9 countries (UNESCO, 2003). In fact, E-9 countries have been successful in making improvements in areas such as school enrolment and literacy rates evaluated by these indicators. According to the 2011 EFA Global Monitoring Report (2011b), for example, between 1999 and 2009, the net enrolment of primary school students among E-9 countries increased from $84 \%$ to $89 \%$, the adult literacy rate increased from $76 \%$ to $80 \%$, and the gender parity index increased from 0.92 to 0.97 . While this improvement may suggest the E-9's relevance to EFA achievements, it cannot indicate exactly how the initiative contributes to successes.

\section{E-9 Initiative}

The E-9 Initiative has been one of UNESCO's EFA coordination pillars, along with the Working Group and High-Level Group meetings. " "E" stands for education and "9" for the 
nine participant countries: Bangladesh, Brazil, China, Egypt, India, Indonesia, Mexico, Nigeria and Pakistan. The E-9 Initiative was launched at the EFA Summit of the Nine High Populated Countries in New Delhi in 1993 as a follow-up to the World Conference on Education for All in Jomtien, Thailand in 1990. The idea of holding a Summit for the leaders of the "largest" and "most populous" countries was first discussed between these leaders and UNESCO’s Director-General Federico Mayor and UNICEF's Executive Director James Grant during the first International Consultative Forum on EFA in December 1991, and a formal offer to host the Summit was received from the Prime Minister of India in September 1992. According to Bibeau et al. (2003), James Grant had the original idea of the E-9 Initiative and Federico Mayor adapted it. While the other EFA convening agencies, notably UNFPA, joined the initiative, it "was established at a highly political level and very rapidly became UNESCO’s responsibility only” (Bibeau et al. 2003, p. 6).

While these countries are the so-called "Nine High Populated Countries," they are not the nine most populated countries in the world (see Table 1). For instance, the Philippines and Vietnam were (and still are) more populated than Egypt. Additionally, they are not the nine poorest countries, either. Some E-9 countries, such as China, India, and Mexico, are no longer developing countries in many aspects. China is the second largest economy and Mexico is a member of the Organization for Economic Cooperation and Development (OECD). India is expected to be the third largest economies in the coming decades.

Table 1. World Population in 1992 and 2011

\begin{tabular}{|c|c|c|c|c|c|}
\hline 1992 & Country & Population (000) & 2011 & Country & Population (000) \\
\hline 1 & China & 1163970 & 1 & China & 1336718 \\
\hline 2 & India & 882821 & 2 & India & 1189173 \\
\hline 3 & US & 256514 & 3 & US & 311705 \\
\hline 4 & Indonesia & 184322 & 4 & Indonesia & 245613 \\
\hline 5 & Brazil & 154254 & 5 & Brazil & 203430 \\
\hline 6 & Russia & 148689 & 6 & Pakistan & 176554 \\
\hline 7 & Japan & 124229 & 7 & Nigeria & 155216 \\
\hline 8 & $\begin{array}{l}\text { Pakistan } \\
\end{array}$ & 113562 & 8 & Bangladesh & 150863 \\
\hline 9 & \begin{tabular}{|l|l|}
9 Bangladesh \\
\end{tabular} & 108921 & 9 & Russia & 13873 \\
\hline 10 & Nigeria & 100103 & 10 & Japan & 126476 \\
\hline 11 & Mexico & 86369 & 11 & Mexico & 112337 \\
\hline 12 & Germany & 80624 & 12 & Philippines & 101834 \\
\hline 13 & 3 Vietnam & 68990 & 13 & Ethiopia & 90874 \\
\hline 14 & Philippines & 63987 & 14 & Vietnam & 87375 \\
\hline 15 & Turkey & 58374 & 15 & Germany & 81472 \\
\hline 16 & \begin{tabular}{|l|} 
Egypt \\
\end{tabular} & 57916 & 16 & Egypt & 80492 \\
\hline
\end{tabular}

Source: Nation Master (2012a); Nation Master (2012b)

Yet, addressing the educational issues of these nine countries is deemed essential for achieving EFA because the E-9 countries represent over half of the world's population, 
two-thirds of the world's illiterate adults, and 42\% of the world's out of school children (see Table 2). It was thus rational to prioritize a group of highly populated countries for the attainment of EFA. ${ }^{v}$

Table 2. E-9 Country Profile

\begin{tabular}{|c|c|c|c|c|c|c|c|c|}
\hline 2009 & $\begin{array}{l}\text { Population (000) } \\
\text { (UNDP Data) }\end{array}$ & $\begin{array}{l}\text { A dult } \\
\text { Iliterates } \\
\text { (age } 15+)\end{array}$ & $\begin{array}{c}\text { Youth } \\
\text { Iliterates } \\
\text { (age 15-24) }\end{array}$ & $\begin{array}{l}\text { Out of P } \\
\text { School C }\end{array}$ & $\begin{array}{l}\text { imary } \\
\text { iildren }\end{array}$ & \begin{tabular}{|c|} 
Primary \\
School- \\
aged \\
Population
\end{tabular} & $\begin{array}{r}\text { Enrolment } \\
\text { Primary Educa }\end{array}$ & $\begin{array}{l}\text { in } \\
\text { ation }\end{array}$ \\
\hline Bangladesh & 162221 & 49036 & 8103 & 1835 & * & 17384 & 16539 & * \\
\hline Brazil & 193734 & 14089 & 740 & & & & 17452 & \\
\hline China & 1345751 & 64604 & 1457 & & & 91908 & 103617 & \\
\hline Egypt & 82999 & 17816 & 2597 & 471 & ** & 10294 & 10407 & \\
\hline India & 1198003 & 283105 & 40681 & 3852 & $\star \star,-1$ & 124696 & 145454 & -1 \\
\hline Indonesia & 229965 & 12858 & 222 & 389 & & 23748 & 29901 & \\
\hline Mexico & 109610 & 5112 & 292 & 61 & -1 & 12746 & 14861 & \\
\hline Nigeria & 154729 & 34845 & 8762 & & $\star \star,-2$ & 24268 & 21714 & \\
\hline Pakistan & 180808 & 50020 & 11000 & 7300 & * & 21704 & 18468 & \\
\hline E-9 & 3657820 & 531485 & 73854 & 28354 & & 341750 & 379115 & ** \\
\hline World & 6769477 & 793090 & 127307 & 67093 & & 654319 & 700960 & \\
\hline$\% \mathrm{E}-9$ to $\mathrm{W}$ & $54,03 \%$ & $67,01 \%$ & $58,01 \%$ & 42,26 & & $52,23 \%$ & $54,09 \%$ & \\
\hline 1999 & $\begin{array}{l}\text { Population (000) } \\
\text { (UNDP Data) }\end{array}$ & $\begin{array}{l}\text { A dult } \\
\text { Iliterates } \\
\text { (age } 15+)\end{array}$ & $\begin{array}{c}\text { Youth } \\
\text { Iliterates } \\
\text { (age 15-24) }\end{array}$ & $\begin{array}{l}\text { Out of P } \\
\text { School C }\end{array}$ & $\begin{array}{l}\text { imary } \\
\text { iildren }\end{array}$ & \begin{tabular}{|c|}
$\begin{array}{c}\text { Primary } \\
\text { School- } \\
\text { aged } \\
\text { Population }\end{array}$ \\
\end{tabular} & $\begin{array}{r}\text { Enrolment } \\
\text { Primary Educa }\end{array}$ & $\begin{array}{l}\text { in } \\
\text { ation }\end{array}$ \\
\hline Bangladesh & 138135 & 48059 & 11335 & & & 17115 & & \\
\hline Brazil & 171675 & 15089 & 1123 & & & 13543 & 20939 & \\
\hline China & 1256729 & 85307 & 2242 & & & 119364 & & \\
\hline Egypt & 68860 & 17620 & 3450 & 1064 & ** & 8729 & 8086 & ** \\
\hline India & 1024799 & 269823 & 48713 & & & 119264 & 110986 & \\
\hline Indonesia & 202513 & 14824 & 538 & & & 25152 & 28202 & ${ }^{*},+1$ \\
\hline Mexico & 98103 & 6452 & 476 & 71 & & 13199 & 14698 & \\
\hline Nigeria & 121836 & 34272 & 8368 & 7611 & ** & 19671 & 17907 & \\
\hline Pakistan & 144516 & 46625 & 12113 & & & 20108 & 13987 & $*,+1$ \\
\hline E-9 & 3227166 & 538071 & 88358 & 48842 & & 356145 & 362023 & \\
\hline World & 6028698 & 791646 & 141985 & 106106 & & 656509 & 644050 & ** \\
\hline$\% \mathrm{E}-9$ to $\mathrm{W}$ & $53,53 \%$ & $67,97 \%$ & $62,23 \%$ & 46,03 & & $54,25 \%$ & $56,21 \%$ & \\
\hline \multicolumn{4}{|c|}{$\begin{array}{r}\text { Note: } 1999 \text { Literacy data refer to the census for the period } 199 \\
2009 \text { Literacy data refer to the census for the period } 200 \text { ! }\end{array}$} & \multicolumn{5}{|c|}{$\begin{array}{l}\text { Legends: }{ }^{*} \text { National estimates }{ }^{* *} \text { UIS Estimates } \\
\pm n: \text { Data refer to } \pm n \text { year from the reference year }\end{array}$} \\
\hline
\end{tabular}

Source: UNESCO Institute for Statistics (2009)

Through establishing partnerships among E-9 countries, the initiative has helped them learn from each other by exchanging information, discussing best practices, and building capacity in order to address existing educational issues of common interest. In the E-9 framework, the Ministerial Review Meetings focused on relevant themes are held every two years. In June 2010, for example, UNESCO and Nigeria organized the Eighth Ministerial Review Meeting in Abuja, Nigeria, focusing on the theme of Literacy for Development. UNESCO and India have been preparing toward the Ninth Ministerial Review Meeting on Inclusive, Relevant Quality Education, which will take place in New Delhi, India in November 2012. ${ }^{\mathrm{vi}}$ 
Since its launch, the E-9 Initiative has gone through many twists and turns. As detailed in the next section, the evaluation report by Bibeau, Kester-Mcnees, \& Reddy (2003) severely criticized the Initiative to the extent that they recommended that it be terminated and all the resources be reallocated to the general EFA programs. In response to the evaluation report, UNESCO (2003) countered the criticisms arguing that the report failed to consider the initiative's contribution to EFA performance within the E-9 countries. Despite its ups and downs, the E-9 Initiative had been frequently discussed, at least until a few years after the turn of the century. However, no evaluation has been conducted since Bibeau et al.'s report in 2003. In fact, not much external literature on E-9 exists. The next section will review a few pieces of literature on the E-9 Initiative in order to further establish a context for an analysis of the Initiative in the EXB and GC documents from 1999 to 2010.

\section{Literature Review}

Apart from the EXB and the GC documents, this research includes the following references: Report on the Evaluation of UNESCO's E-9 Initiative (Bibeau et al. 2003); Note on the E-9 Initiative (UNESCO 2003); and Enhancing Effectiveness of EFA Coordination (UNESCO 2011a). Bibeau et al.'s Report is an independent external review based on interviews with those who work for organizations, such as E-9 Ministries and UN agencies. The Note on the E-9 Initiative was prepared by the E-9 Secretariat at UNESCO Headquarters in order to argue against Bibeau et al.'s review. The Enhancing Effectiveness of EFA Coordination was prepared by UNESCO's EFA Global Partnerships Team as a response to the request from the Member States to improve the EFA coordination mechanisms, including E-9.

Bibeau et al.'s report questions the effectiveness and the impact of the initiative. For instance, they argue that although the main purpose of the E-9 Initiative is to establish partnerships among E-9 countries, "nothing demonstrates that any networking took place" (19) and few participants consider that the initiative "necessarily correspond[s] to their needs" (19). They conclude that "it is recommended to terminate the Initiative and to embed the resources allocated to the Initiative in the general EFA program” (d).

Their criticism has a point in that the initiative's contribution to EFA is not well recognized. Although many themes discussed in the E-9 context, such as literacy and teacher education, are important and relevant to EFA, and all E-9 countries have made progress toward the attainment of EFA, it has not always been clear how the E-9 Initiative and its related-activities have contributed to improve the educational conditions of these countries, in part due to a lack of monitoring and evaluation. UNESCO's EFA Global Partnerships Team, the Secretariat of the E-9 Initiative, is aware that this issue has to be addressed for improvement. For instance, E-9 countries are now asked to submit not only the national reports for the preparation of the Ministerial Review Meetings but also the progress report on previous topics. Also, expert group and senior officials meetings are periodically held in an attempt to monitor and evaluate the activities and programs implemented by the E-9 countries. Most recently, a Senior Officials Meeting was held in Abuja, Nigeria in December 2011.

While UNESCO recognizes the issue of insufficient monitoring and evaluation of the Initiative, the organization points out that two key dimensions of objective analysis are absent 
from Bibeau et al.'s evaluation report: 1) an examination of the original aims and unfolding development of the initiative on the basis of a thorough document review and 2) an examination of the EFA performance of E-9 countries in the light of statistical data and other available information. While UNESCO acknowledges that "no direct or automatic correlation between these EFA developments and the E-9 Initiative should be drawn," it argue that "this snap-shot of EFA trends and related developments may suggest that, at the very least, the E-9 Initiative has not been irrelevant to EFA performance" (UNESCO 2003, p. 3) Yet, the issue of measuring the contribution of the E-9 Initiative to EFA remains to be addressed. As UNESCO (2011b) explains, it is difficult to identify the causal relationship between EFA coordination and EFA performance. While there are a number of issues, such as uneven involvement of the EFA convening agencies and weak coordination linkages between the national, regional, and global levels, to be addressed in order to improve the effectiveness of the existing EFA coordination mechanisms, the successful key factors are hardly acknowledged. UNESCO uses the term "visibility" to describe how influential and thus successful the organization's work is in promoting education. The next section will expound the term visibility and how it can be evaluated.

\section{Methodology}

Documentary research was conducted on the E-9 issues discussed in the EXB and GC documents between 1999 and 2010 in order to answer the following research questions: How many EXB and GC documents and their sections describe the E-9 issues? How often does the term "E-9" appear in the documents? In what context are they discussed? With all these other questions in mind, has the E-9 Initiative become more visible or less visible during the period? This paper focuses on "Decisions" and "EX4" in the EXB documents and "Proceedings," "Resolutions" and "Program and Budget (C/5)" in the GC documents despite the fact that the E-9 issues are sometimes addressed in other documents (e.g., 174 EX10). It is also important to note that although there were 30 Executive Board meetings (156-185) between 1999 and 2010, this research covers only 24 because there were three EXBs in the years of General Conferences (1999; 2001; 2003; 2005; 2007; 2009), which are dedicated to the organization of the EXB and the GC rather than information regarding specific programs or initiatives. Thus, they are excluded from this research. With regard to the GC, this research analyzed all of the documents (30-35) between 1999 and 2010.

\section{Results}

\section{Results: the EXB Documents}

Out of the 24 documents considered, 22 include a section regarding the E-9 and the term "E-9." On average, approximately 2.5 sections in each document mentioned E-9 in various contexts such as EFA and SSC. The term "E-9" appeared an average of 5.5 times in each document. It is noteworthy that the frequency of the term "E-9" has drastically decreased since 2007. The last ten EXBs (177-185), for example, included the term "E-9" only once on average, while the previous seven EXBs (165-176) included the term more than eight times on average. Given the number of sections dealing with the E-9 Initiative and the number of times the term "E-9" is mentioned combined, the peak of the initiative may have been in the 


\section{Macrothink}

Journal of Studies in Education

ISSN 2162-6952

2012, Vol. 2, No. 4

early 2000s, though the frequency of the term "E-9" remained consistently high throughout the researched period until 2007.

Table 3. E-9 in EXB

\begin{tabular}{|c|c|c|c|c|}
\hline EXB & Year & \begin{tabular}{|c|}
$\begin{array}{c}\text { Number of } \\
\text { sections with E-9 }\end{array}$ \\
\end{tabular} & \begin{tabular}{|} 
Number of \\
terms "E-9"
\end{tabular} & Context \\
\hline 156 & 1999 & 2 & 7 & EFA \\
\hline 157 & 1999 & 2 & 10 & MRM \\
\hline 158 & 1999 & & & \\
\hline 159 & 2000 & 1 & 1 & \\
\hline 160 & 2000 & 1 & 4 & EFA / MRM \\
\hline 161 & 2001 & 2 & 5 & EFA \\
\hline 162 & 2001 & 4 & 12 & EFA / MRM / SSC \\
\hline 163 & 2001 & & & \\
\hline 164 & 2002 & 2 & 6 & MRM / ICT \\
\hline 165 & 2002 & 3 & 4 & EFA \\
\hline 166 & 2003 & 4 & 7 & EFA \\
\hline 167 & 2003 & 2 & 8 & EFA / ECCE \\
\hline 168 & 2003 & & & \\
\hline 169 & 2004 & 6 & 14 & EFA / MRM / ECCE \\
\hline 170 & 2004 & 3 & 5 & EFA / MRM \\
\hline 171 & 2005 & 4 & 10 & EFA / MRM / ICT \\
\hline 172 & 2005 & 5 & 14 & EFA / MRM / ICT / ECCE \\
\hline 173 & 2005 & & & \\
\hline 174 & 2006 & 6 & 7 & EFA / MRM / SSC \\
\hline 175 & 2006 & 2 & 2 & EFA / SSC / ICT / MDG \\
\hline 176 & 2007 & 6 & 6 & EFA / MRM / SSC / MDG \\
\hline 177 & 2007 & 1 & 1 & MRM \\
\hline 178 & 2007 & & & \\
\hline 179 & 2008 & 2 & 2 & MRM / SSC \\
\hline 180 & 2008 & 1 & 1 & \\
\hline 181 & 2009 & 1 & 3 & MRM / SSC \\
\hline 182 & 2009 & 0 & 0 & \\
\hline 183 & 2009 & & & \\
\hline 184 & 2010 & 0 & 0 & \\
\hline 185 & 2010 & 1 & 1 & MRM \\
\hline
\end{tabular}


Table 4. E-9 in GC

\begin{tabular}{|r|r|r|r|l|}
\hline GC & Year & $\begin{array}{c}\text { Number of } \\
\text { section with E-9 }\end{array}$ & $\begin{array}{l}\text { Number of } \\
\text { term "E-9" }\end{array}$ & \multicolumn{1}{|c|}{ Context } \\
\hline 30 & 1999 & 11 & 17 & $\mathrm{EFA} / \mathrm{MRM} / \mathrm{SSC}$ \\
\hline 31 & 2001 & 18 & 34 & $\mathrm{EFA} / \mathrm{MRM} / \mathrm{ICT} / \mathrm{ECCE}$ \\
\hline 32 & 2003 & 18 & 33 & $\mathrm{EFA} / \mathrm{MRM} / \mathrm{ICT}$ \\
\hline 33 & 2005 & 15 & 27 & $\mathrm{EFA} / \mathrm{MRM} / \mathrm{ICT}$ \\
\hline 34 & 2007 & 10 & 11 & $\mathrm{EFA} / \mathrm{SSC}$ \\
\hline 35 & 2009 & 3 & 5 & $\mathrm{EFA} / \mathrm{MRM} / \mathrm{SSC}$ \\
\hline
\end{tabular}

EFA=Education for All; MRM=Ministerial Review Meeting; SSC=South-South Cooperation; ICT=Information and Communication Technology; ECCE=Early Childhood Care and Education; MDG=Millennium Development Goals

\section{Results: the GC Documents}

As was the case with the EXB documents, the E-9 Initiative has been discussed less frequently since 2007. Although the GC documents between 1999 and 2005 included 15.5 sections discussing the E-9 Initiative on average, the GC documents in 2007 and 2009 included only 6.5 sections on average. Within the seven sections of the GC documents between 1999 and 2005, the term "E-9" was mentioned on average 27.5 times while only being mentioned eight times on average in 2007 and 2009. Among the GC documents (30-35) researched, 32 C/5 in 2003 particularly draws attention. It includes an entire section under the title of "Funding activities in and for E-9 countries: A synoptic overview which describes the history, the objective, and the budget of the E-9 Initiative."

\section{Discussion}

While the E-9 Initiative seems to remain one of UNESCO's EFA coordination pillars, neither UNESCO nor its Member States mention E-9 in official events and documents any more. Yet, does the invisibility of E-9 indicate that EFA activities in E-9 countries are invisible as well? The growing invisibility of the E-9 Initiative led me to consider whether the initiative was actually becoming less important or whether the term "E-9" was being replaced by another term "SSC," which started appearing frequently in the EXB and GC documents in the late 2000s.

Although further research may need to be conducted to elucidate the relationship between E-9 and SSC, this study suggests that as the visibility of E-9 decreased, that of SSC increased. The issues of E-9 countries activities are now often correlated with SSC (See Table 3 and 4). EXB 174 EX Decisions (2006, p. 8), for example, states that as a "facilitator, innovator, and catalyst for South-South cooperation in education," UNESCO's role in this initiative is to "provide an umbrella under which better South-South collaboration may thrive among E-9 countries" by engaging these countries "as strategic partners to achieve the EFA goals." Given a number of EFA-related activities in E-9 countries, it is possible to argue that E-9 countries now implement programs, such as literacy and teacher education, without being 


\section{IMacrothink}

aware of or mentioning the E-9 Initiative. As a result, while the E-9 Initiative may still serve as a pivotal platform for enhancing SSC, SSC in turn may obscure the visibility of the E-9 Initiative.

In order to examine whether the Initiative has become actually less important or whether the term has been replaced by SSC, I conducted research on the term "SSC" using the same methodology that has been used with the term E-9 in the same documents. The results are drawn for comparison between E-9 and SSC in the Figure 1 and Figure 2.

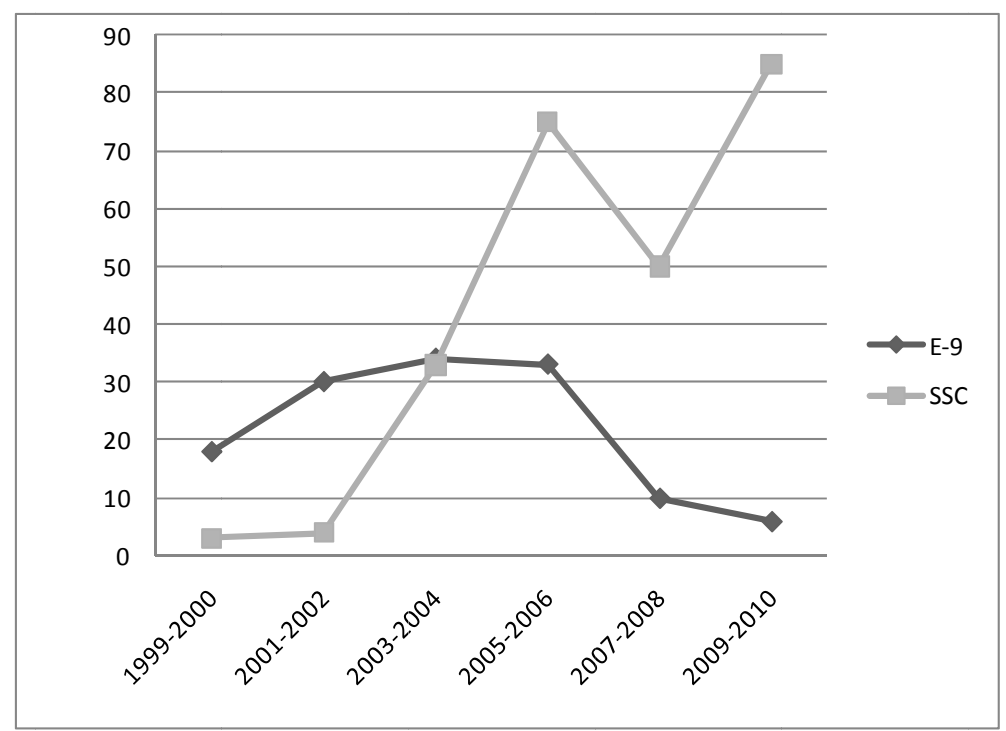

Figure 1. E-9 and SSC in EXB Documents

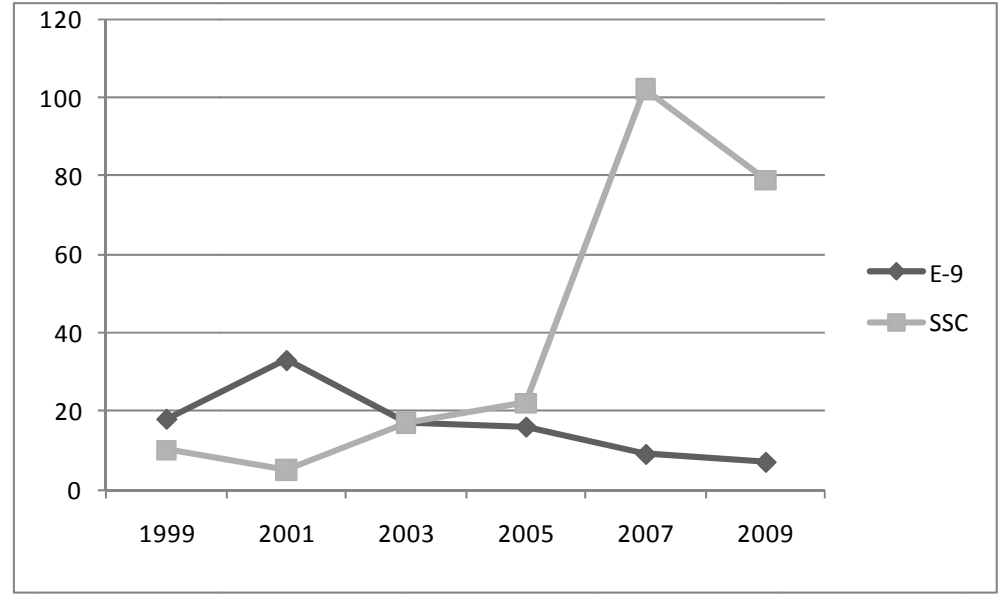

Figure 2. E-9 and SSC in GC Documents

In terms of the frequency of the term "E-9" and "SSC" in the EXB documents (Decisions and EX4) between 1999 and 2010, the ratio of E-9 to SSC was 87.3\% (48:7) between 1999 and 2002, 45.6\% (67:80) between 2003 and 2006 and 9.4\% (14:135) between 2007 and 2010. The 
case is similar with the GC documents. The ratio of E-9 to SSC was 77.2\% (51:15) in 1999 and 2001, 45.8\% (33:39) in 2003 and 2005 and 8.1\% (16:181) in 2007 and 2009. This shows the inverse proportion between SSC and E-9: as SSC became more visible, the E-9 Initiative became less visible.

The turning point occurred between 2006 and 2007. Before that period, SSC had generally been mentioned in the E-9 context, and since then, E-9 seems to have appeared in the SSC context. The SSC related events such as the first UN conference on South-South Cooperation in 2004 and the establishment of South-South Cooperation might have augmented the visibility of SSC.

Accepting that SSC has gained more visibility in the context and work previously filled by the E-9 Initiative, some questions arise. Should UNESCO let SSC take over the E-9 Initiative because the former embraces the latter? Has E-9 completed its mission to provide opportunities for networking and information exchange, mainly due to the advancement of technology? Is there any way that E-9 and SSC can mutually enhance their functions?

\section{Conclusion}

This research demonstrated that while E-9 is still present in the EXB and GC documents, its visibility has weakened notably since 2007. The comparison of the visibility between the E-9 Initiative and SSC shows that the E-9 Initiative's visibility has weakened as that of SSC has strengthened. While the relationship between them remains unclear, the increased visibility of SSC may be attributed to the decreased visibility of the E-9 Initiative. Given that the E-9 Initiative was one of the driving forces for SSC and EFA, the increased visibility of SSC may be a success of the Initiative. At the same time, with the absence or weakening of the E-9 Initiative, it might be more difficult for the maintained visibility and success of SSC. Further research will be required to follow up the latest and future trends in E-9 and SSC.

\section{References}

advocacy. (2012). Oxford English Dictionary. Retrieved on November 6, 2012 from http://oxforddictionaries.com/definition/english/advocacy?q=advocacy

Bibeau, J., Kester-Mcnees, \& Reddy, R. (2003). Report on the Evaluation of UNESCO's E-9 Initiative. Unpublished paper commissioned by UNESCO.

coordination. (2012). Oxford English Dictionary. Retrieved on November 6, 2012 from http://oxforddictionaries.com/definition/english/coordination?q=coordination

Nation Master. (2012a). Population (1992) by county. Retrieved on September 27, 2012 from http://www.nationmaster.com/graph/peo-pop-people-population\&date=1992

Nation Master. (2012b). Population (2011) by country. Retrieved on September 27, 2012 from http://www.nationmaster.com/graph/peo-pop-people-population\&date=2011

UNESCO Institute for Statistics. (2011). E-9 Country Profiles. Unpublished data by UNESCO Institute for Statistics. 


\section{Macrothink}

UNESCO. (2003). Note on the E-9 Initiative. Unpublished paper commissioned by UNESCO.

UNESCO. (2003). 32 C/5. Paris: UNESCO.

UNESCO. (2006). 174 EX/10. Paris: UNESCO.

UNESCO. (2011a). Enhancing Effectiveness of EFA Coordination. Paris: UNESCO.

UNESCO. (2011b). EFA Global Monitoring Report - Hidden Crisis. Paris: UNESCO and Oxford University Press.

UNESCO. (2012). Advocacy. Retrieved on 27 September, 2012 from http://www.unesco.org/new/en/education/themes/leading-the-international-agenda/education for-all/advocacy

\section{Copyright Disclaimer}

Copyright reserved by the author(s).

This article is an open-access article distributed under the terms and conditions of the Creative Commons Attribution license (http://creativecommons.org/licenses/by/3.0/).

\footnotetext{
${ }^{\mathrm{i}}$ It is worth noting that the "visibility" discussed here is within UNESCO itself. It does not necessarily represent what development organizations, national governments, and other stakeholders perceive outside of UNESCO know about the work of the E-9 Initiative.

ii The EXB is one of the governing bodies of UNESCO. It is elected by the GC and acts under the authority of the GC. The EXB examines UNESCO's programs and corresponding budget estimates. It consists of 58 UNESCO Member States, each holding a four-year term of office (i.e. the countries comprising the EXB change every four years). It meets twice a year except during GC years, when it meets additional times after the GC. The GC consists of the representatives of all 195 UNESCO Member States. It meets every two years and is attended by Member States and Associate Members, with observers from non-Member States, intergovernmental organizations, and non-governmental organizations (NGOs).

iii There are six EFA goals that were declared in the Dakar Framework for Action during the World Education Forum in 2000: 1) expand and improve comprehensive early childhood care and education; 2) ensure that all children have access to, and complete, free and compulsory primary education; 3) ensure that the learning needs of all young people and adults are met through appropriate learning and life skills programs; 4) achieve 50\% improvement in levels of adult literacy; 5) eliminate gender disparities in primary and secondary education by 2005 and achieve gender equality in education by 2015; and 6) improve all aspects of quality of education. The Global Monitoring Report uses the EFA Development Index (EDI) as a measuring tool, composed of universal primary education, adult literacy, quality of education based on the survival rate to grade 5, and gender parity, to evaluate EFA performance.

iv The Working Group meeting on EFA provided technical guidance and information exchange between all EFA partners. Comprised of some forty key actors, including representatives of governments, bilateral and multilateral donor agencies and
} 
non-governmental organizations, it was chaired by UNESCO’s Assistant Director-General for Education. The High-Level Group meeting was an annual event bringing together high-level representatives from national governments, development agencies, UN agencies, civil society, and the private sector. Its role was to generate political momentum and mobilize financial, technical and political support toward the achievement of the six EFA goals. The Working Group and the High-Level Group meetings have now been replaced with the Global EFA Meeting (GEM).

$\checkmark$ Bibeau el al. (2003) explains that the selection of E-9 members was due to the geographical balance for networking: "[it was] necessary to include countries from other regions in order not to create an impression of favouring one region in particular” (p. 6) and some of the countries "had already resolved the same issue with which the nine countries were struggling; in this manner the nine countries could use the others as model of success" (p. 7).

vi Since its launch in 1993, the E-9 countries have met eight times. The previous conferences were on: Teacher Education and Training (Bali, Indonesia, October 2008); Policies and Systems for the Assessment of the Quality of Education (Monterrey, Mexico, February 2006); Early Childhood Education (Cairo, Egypt, December 2003); Use of Distance Education and Information and Communication Technologies (ICTs) in Education (Beijing, China, August 2001); EFA 2000 Assessment (Recife, Brazil, January and February 2000); Social and Political Mobilization (Islamabad, Pakistan, September 1997); and From Delhi to Bali (Bali, Indonesia, September 1995). 